\title{
What are the Principles for Assigning Authorship?
}

\author{
Seung Yong Song
}

Deputy Editor, Archives of Plastic Surgery

Department of Plastic and Reconstructive Surgery, Yonsei University College of Medicine, Seoul, Korea

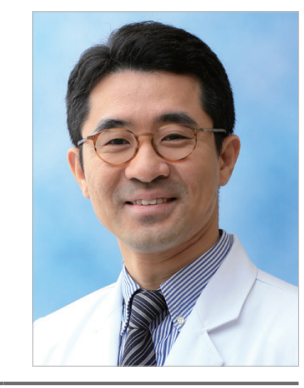

Authorship is very important because academic achievement often assessed in terms of published articles, and the authors of each article are considered to have played a principal role in clinical or experimental studies. It is reasonable that readers of a journal think that authors are experts in their field of study.

However, the editorial office of Archives of Plastic Surgery (APS) sometimes receives letters requesting modifications of the authorship of an article, including addition, removal, and changing the order of authors. This is an awkward situation for the journal office. In many high-quality journals, author modification is not easy and can only be permitted with justifiable grounds. Some journals even request a description of the role of each author specifically to ensure fair attribution of authorship in the manuscript submission process. For example, an author can play a role in study conception and design, analysis and interpretation of the data, drafting the article, critical revisions for important intellectual content, final approval of the article, statistical expertise, and/or collection and assembly of the data. What, then, is the consensus for assigning authorship correctly?

In 2013, the International Committee of Medical Journal Editors suggested 4 principles for defining authorship [1].

1. Substantial contributions to the conception or design of the work, or the acquisition, analysis, or interpretation of data for the work; AND

2. Drafting the work or revising it critically for important intellectual content; AND

3. Final approval of the version to be published; AND

4. Agreement to be accountable for all aspects of the work in ensuring that questions related to the accuracy or integrity of any part of the work are appropriately investigated and re- solved.

Those who do not meet all 4 criteria should be acknowledged. The provision of funding does not make an individual eligible for authorship. The same holds for general supervision or proofreading.

The first author is held to have made the greatest contribution to the research.

The corresponding author is the individual who takes primary responsibility for communication with the journal during the manuscript submission, peer review, and publication process, and who typically ensures the proper completion of all the journal's administrative requirements, such as providing authorship details, ethics committee approval, clinical trial registration documentation, and conflict of interest forms and statements, although these duties may be delegated to 1 or more coauthors. The corresponding author should be available throughout the submission and peer review process to respond to editorial queries in a timely manner, and should be available after publication to respond to critiques of the work and cooperate with any requests from the journal for data or additional information should questions about the paper arise after publication [1].

The order of the authors is arranged by the joint decision of the co-authors. Authors should sometimes prepare a rationale for the determination of the author order, and each author should sign an agreement about the order of the authors [2]. In some cases, it is permitted to have multiple first or corresponding authors, based on the policy of the journal. Thus, if the correct process is used when drafting a manuscript, mistakes in authorship can be minimized.

Examples of unfair authorship exist. The term "gift author" re- 
fers to people who are listed as authors but who did not make a significant contribution to the research. These are often senior figures. The term "ghost author" usually refers to professional writers whose role is not acknowledged [3]. The term "swap author" refers to authorship without a significant role in the giveand-take relationship between researchers.

In the past, some authors did not appreciate the criteria underlying the fair assignment of authorship. However, authorship has become one of the most important issues in the publication process of modern medical journals. Every author published in APS should be aware of the principles of authorship in the submission process.

\section{ORCID}

Seung Yong Song http://orcid.org/0000-0002-3145-7463

\section{REFERENCES}

1. International Committee of Medical Journal Editors. Defining the role of authors and contribution [Internet]. Interna- tional Committee of Medical Journal Editors; 2016 [cited 2016 Dec 26]. Available from: http://www.icmje.org/recommendations/browse/roles-and-responsibilities/defining-therole-of-authors-and-contributors.html.

2. Bae JW. Publication ethics which editors should know. Proceeding of the 9th Korean Academy of Medical Journal Editors; 2015 Dec 5; Seoul, Korea.

3. Springer. Authorship issues-guest, gift or ghost [Internet]. New York: Springer International Publishing AG; 2016 [cited 2016 Dec 26]. Available from: http://www.springer.com/ $\mathrm{gp} /$ authors-editors/authorandreviewertutorials/biomedcentral-editor-tutorials/publication-and-research-ethics-andmisconduct/authorship-issues-guest-gift-or-ghost.

Correspondence: Seung Yong Song

Department of Plastic and Reconstructive Surgery, Yonsei University College of Medicine, 50Yonsei-ro, Seodaemun-gu, Seoul 03722, Korea

Tel: +82-2-2228-2225, Fax: +82-2- 393-6947, E-mail: iceberg554@ naver.com

No potential conflict of interest relevant to this article was reported.

Received: 23 Dec 2016• Revised: 23 Dec 2016 • Accepted: 23 Dec 2016 pISSN: 2234-6163 • elSSN: 2234-6171

https://doi.org/10.5999/aps.2017.44.1.3 • Arch Plast Surg 2017;44:3-4 